\title{
Maternidade e hanseníase: as vivências de separação devido ao isolamento compulsório
}

\author{
Suellen Santos Lima de Almeida \\ Fiocruz Minas \\ Leonardo Cançado Monteiro Savassi \\ Universidade Federal de Ouro Preto \\ Virgínia Torres Schall \\ Fiocruz Minas \\ Celina Maria Modena \\ Universidade Federal de Minas Gerais
}

\begin{abstract}
Resumo
As mulheres portadoras de hanseníase, durante grande parte do século XX, não puderam exercer a maternidade devido à política de isolamento compulsório dos doentes adotada para controlar a doença. Os filhos ao nascerem eram levados para os preventórios e o contato com estes era realizado pelo olhar. Visando compreender a experiência da maternidade no hospital colônia foi realizada pesquisa narrativa com três mães que viveram o período de internação compulsória. Os discursos revelam dois momentos distintos da vivência de maternidade: a separação dos filhos com sua posterior volta para casa e a adoção de crianças para realizar a maternidade. Considera-se que a adoção promoveu o encontro com o sentido da existência que havia sido rompido e possibilitou a experiência de ser-mãe.
\end{abstract}

Palavras-chave: maternidade; hanseníase; sentido.

\begin{abstract}
Being a mother with leprosy: the experiences of separation due to compulsory isolation. In the twentieth century, women with leprosy could not carry on their maternity because of the statement of compulsory isolation of patients, adopted to control the disease. Their children were taken at birth to prevention centers and the contact of mothers with their babies was only visual. In order to understand the experience of maternity in the leprosaria it was carried out an investigated narrative research with three mothers who lived through the period of compulsory internment. The speeches reveal two distinct moments in the experience of motherhood: the separation of the children with their subsequent return to home and the adoption of other children to achieve motherhood. It is considered that the adoption has promoted the meeting with the meaning of existence that had been broken and allowed the experience of being a parent.
\end{abstract}

Keywords: motherhood; leprosy; sense.

\section{Introdução}

Desde a antiguidade, os portadores de hanseníase sofreram exclusão social e o preconceito da sociedade em relação à doença, seja por expulsão das cidades, reclusão nos leprosários e até mesmo por sua morte como cidadão. A visão medieval da lepra e do portador da doença atravessou os séculos e medidas de exclusão ao leproso continuaram a ser praticadas em nome do bem estar da coletividade (Monteiro, 1998).

Com o aumento dos casos de "lepra" em todo o mundo as autoridades começaram a se preocupar com medidas de tratamento dos doentes e de contenção da doença. No século XIX, apesar dos avanços no conhecimento da doença, as formas de transmissão e de tratamento ainda eram desconhecidas (Savassi, 2010). A primeira política de isolamento dos leprosos foi proposta por Amauer Hansen na I Conferência Internacional da Lepra, no ano de 1897, em Berlim (Santos, Faria, \& Menezes, 2008).

No Brasil, a atenção aos portadores de lepra era realizada por instituições religiosas ou filantrópicas que tinham por objetivo recolher e dar assistência aos leprosos e proteger a sociedade sadia dos doentes. O alto custo para o diagnóstico e o tratamento fazia da lepra uma questão de saúde pública, diante da qual o Estado deveria organizar uma política de prevenção e tratamento (Ducatti, 2009; Opromolla \& Laurenti, 2011). A virada do século XIX para o século XX acarretou uma revolução 
na maneira como o governo trataria a hanseníase, caminhando para políticas de isolamento e segregação que culminaram em práticas discriminatórias (Eidt, 2004).

A criação de colônias agrícolas foi sugerida em 1919 pela Associação Médico-Cirúrgica do Rio de Janeiro. As colônias deveriam ter condições apropriadas para a segregação dos doentes, medidas para impedir os casamentos destes e a proibição do comércio de produtos manipulados por eles (Savassi, 2010). Até 1920 surgiram os primeiros planos profiláticos e os debates sobre as formas de isolamento dos doentes se intensificaram em torno da criação dos hospitais-colônias (Ducatti, 2009).

Durante o Governo Vargas (1930-1945), a profilaxia da "lepra" se baseava no tripé leprosários/preventórios/dispensários. Aos leprosários cabia o isolamento compulsório de todos os casos, os preventórios dedicavam-se ao cuidado, à educação e à observação dos filhos de doentes e os dispensários realizavam o diagnóstico da doença e o encaminhamento para o isolamento dos doentes (Castro \& Watanabe, 2009). Os leprosários eram vinculados ao governo federal, os dispensários estavam a cargo dos serviços sanitários estaduais e os preventórios eram administrados pelas Sociedades de Assistência aos Lázaros e Defesa Contra a Lepra (Santos, 2006).

Na década de 1940, surgem as sulfonas, medicamento que possibilitava o tratamento ambulatorial dos doentes (Opromolla \& Laurenti, 2011). Apesar dos avanços científicos, a internação compulsória continuava a ser utilizada como estratégia terapêutica (Castro \& Watanabe, 2009). Em 1949, foi criada a lei que definia as medidas de profilaxia da lepra que compreendia o isolamento compulsório de todos os acometidos, a vigilância e o controle de todos os suspeitos, a notificação compulsória de todos os casos e o afastamento dos menores das fontes de contágio (os pais) (Savassi, 2010).

Com a internação dos pais nas colônias, as crianças sadias muitas vezes não tinham para onde ir, pois os demais familiares, devido ao estigma da doença, se recusavam a cuidar de tais crianças pelo medo do contágio (Monteiro, 1998). Coube ao Estado criar dispositivos que regulassem o "destino" desses filhos da hanseníase.

Os preventórios eram vistos como uma importante medida de profilaxia, pois o afastamento da criança do convívio com os pais ou parentes hansenianos consistia uma forma de assegurar o controle da doença (Agrícola, 1943). Tal afastamento era realizado assim que os pais ou a criança fossem diagnosticados com a hanseníase. Quando os pais eram portadores da doença, logo após o nascimento, as crianças eram levadas para os preventórios, conforme disposto na legislação:

Os filhos de doente de lepra, logo após o nascimento, embora um só dos progenitores seja doente, serão separados e mantidos até à adolescência, quer em vigilância em domicilio, quer em preventórios especiais que, quando localizados na área do estabelecimento, ficarão anexos à zona de habitação das pessoas sãs, não podendo em caso algum ser nutridos no seio de uma ama, nem amamentados pela própria mãe, se esta estiver doente de lepra. (Decreto $\mathrm{n}^{\circ} 7558,11.11 .1938$ )

$\mathrm{O}$ afastamento da criança de sua família era realizado sob a crença de que a criança, por já ter tido contato com o foco da doença através da mãe, poderia desenvolver a "lepra". Dessa forma, o afastamento da criança consistiria uma forma de evitar que a mesma desenvolvesse a doença. Nos preventórios, as crianças eram cuidadas por pessoas sadias, geralmente freiras, e o contato físico e afetivo com os pais não eram estimulados (Monteiro, 1998).

As medidas de profilaxia realizadas através do isolamento compulsório não consideravam as relações sociais dos indivíduos acometidos pela doença, fazendo com que laços familiares fossem desfeitos, o que causou impacto tanto na vida dos hansenianos como de seus familiares. A internação compulsória causava reflexos diretos no comportamento dos doentes, pois estes se encontravam numa situação de desamparo familiar (Monteiro, 1998).

Socialmente, a maternidade é percebida como o papel fundamental da mulher (Maux \& Dutra, 2009). As representações da maternidade podem ser explicadas através do processo de socialização das meninas que desde pequenas são treinadas para realizarem o cuidado de si e dos outros. Nas brincadeiras infantis, frequentemente estão com o "bebê" no colo, alimentando-o e cuidando das necessidades fisiológicas. Esse papel de cuidadora do outro é internalizado por muitas mulheres como uma meta a ser alcançada, algo que trará a realização pessoal, um sentido para sua vida. A mulher aprende que a dedicação aos filhos é sua atividade mais nobre (Maux \& Dutra, 2009).

As mulheres que foram portadoras da hanseníase, durante grande parte do século XX, não tiveram a possibilidade de realizar o papel materno de cuidadora. A dedicação e o cuidado dirigidos aos filhos esbarraram nas políticas isolacionistas adotadas pelo Estado para conter a hanseníase.

$\mathrm{Na}$ busca por vivenciar seu papel de mãe, várias mulheres encontraram em uma nova gravidez ou na adoção a possibilidade de dar sentido à vida atravessada pelo sofrimento causado pelo afastamento ou pela perda dos filhos. Esta capacidade de passar pelo sofrimento e conseguir superá-lo é descrito na literatura como resiliência (Angst, 2009; Yunes, 2003).

$\mathrm{O}$ encontro com mulheres residentes de um ex-hospitalcolônia, que abrigou no período de internação compulsória os portadores de hanseníase, levou-nos a refletir sobre a questão da maternidade, que por medidas profiláticas não pôde ser exercida por essas mulheres. Discutiremos neste artigo as vivências de separação dos filhos e a adoção como a estratégia de enfrentamento, utilizada pelas mulheres hansenianas para significarem o papel de mãe e dessa forma resgatar os sentidos da maternidade em suas vidas.

\section{Método}

\section{Delineamento e participantes}

O estudo caracteriza-se como qualitativo, utilizando a pesquisa narrativa descrita por Dutra (2002), em que o sujeito conta os fatos, acontecimentos e afetos que percorrem sua trajetória existencial. O pesquisador recolhe a experiência numa tentativa de compreendê-la ao invés de buscar explicações. Este procedimento metodológico, fundamentado nas ideias fenomenológicas e existenciais, possibilita uma aproximação 
da vivência do sujeito através da rememoração de sua história pessoal e da reconstrução dos significados que constituem seu estar-no-mundo.

Visando compreender a experiência da maternidade em um hospital colônia, foram entrevistadas mulheres viúvas, na faixa etária entre 60 e 80 anos, com sequelas de hanseníase, que viveram o período de internação compulsória. Escolheram-se três narrativas que permitiram sustentar o enfoque biográfico da vivência de maternidade neste contexto.

\section{Local do estudo: descrição histórica}

Os encontros e as entrevistas foram realizados em uma ex-colônia. Inaugurada em 1931, a Colônia foi construída em local geograficamente distante do centro do município, entre dois rios para evitar que as pessoas entrassem ou evadissem. Suas principais vias de acesso eram as estradas de ferro. Conforme descrito em documento elaborado pelo Movimento de Reintegração das Pessoas Atingidas pela Hanseníase MORHAN, durante o transporte os pacientes eram mantidos isolados dos demais passageiros, sendo destinado a eles um vagão específico (MORHAN, 2006).

Os doentes eram levados para os pavilhões conforme o gênero e o ciclo de vida. Dessa forma, havia o pavilhão das mulheres e o pavilhão dos homens, que conforme relatos dos moradores eram divididos também por faixa etária, de modo que os adolescentes não ficassem juntos com os adultos e os idosos. Os casais, desde que sendo ambos moradores da colônia, podiam morar em casas ou pensões dentro da colônia (Figueiredo, 2005).

As crianças nascidas dos casamentos entre os hansenianos da Colônia Santa Izabel, ou que tivessem seus pais lá internados, eram levadas para o Preventório. A segregação estendia-se também para os filhos dos pacientes que mesmo não sendo portadores da doença sofreram com o estigma da doença de seus familiares (Guerra, Moreira, \& Diniz, 2002).

Segundo o Movimento de Reintegração das Pessoas Atingidas pela Hanseníase (MORHAN, 2006), a vida dentro da Colônia Santa Izabel era comparada a uma prisão: os pacientes, mantidos sob constante vigilância, com regras de convivência rígidas, perdiam suas identidades e o contato com o mundo externo. A saída da colônia, bem como os casamentos, dependia de autorização da administração. Os filhos, não portadores da doença, eram recolhidos aos preventórios e doados sem a autorização dos pais.

No ano de 1977 os portões foram abertos, o que garantiu liberdade para os moradores e a volta dos filhos que estavam morando no preventório (Figueiredo, 2005).

\section{Instrumento}

Foram realizadas entrevistas abertas, por se configurarem como um convite às concepções, opiniões, pensamentos e sentimentos das participantes do estudo (Benjamin, 2004). Utilizou-se a seguinte pergunta deflagradora "Como foi vivenciar a maternidade na Colônia Santa Izabel?”.

\section{Procedimentos}

A coleta de dados foi realizada por duas psicólogas integrantes da equipe de pesquisa. As entrevistas ocorreram em encontro único com cada participante, em suas residências e duraram em média 40 minutos. Todas as narrativas foram gravadas e, posteriormente, transcritas por uma pesquisadora e revisadas pelas responsáveis pela coleta dos dados.

A pesquisa foi aprovada pelo Comitê de Ética do Centro de Pesquisas René Rachou/ Fundação Oswaldo Cruz - Minas Gerais (Parecer 19/2009) considerando o disposto na Resolução 196/96, do Conselho Nacional de Saúde, que dispõe sobre Diretrizes para Pesquisas em Seres Humanos no Brasil. As entrevistadas foram esclarecidas sobre a confidencialidade das informações prestadas e seus nomes foram trocados por nomes de pedras preciosas.

\section{Análise dos dados}

A compreensão das narrativas se baseou no referencial metodológico da análise existencial de Viktor Frankl (1984) e da teoria da resiliência (Antoniazzi, Dell'Aglio, \& Bandeira, 1998). Sobrevivente de um campo de concentração nazista, Frankl desenvolve sua teoria em torno da busca por um sentido da vida que, para o autor, pode ser descoberto através da criação de um trabalho, do encontro com alguém e da atitude do sujeito perante o sofrimento inevitável (Frankl, 1984). É a busca por um sentido que constitui a motivação principal para a pessoa construir a resiliência (Silveira \& Mahfoud, 2008).

\section{Resultados e discussão}

Observou-se que as mães relatam suas vivências de maternidade em dois momentos: um caracterizado pela separação dos filhos, que foram levados para o preventório, e outro caracterizado pela volta desses filhos para casa e/ou na adoção de crianças para realizar o sonho de ser mãe. Nessas perspectivas foram construídas duas categorias: Mães sem filhos: a busca pelo sentido da maternidade; e Mães com filhos: o reencontro com o sentido de ser mãe.

Mães sem filhos: a busca pelo sentido da maternidade. Kimura (1997) ao estudar a identidade materna ressalta que para a construção do papel social de mãe é necessário que a mulher vivencie desde o início os vários estágios na aquisição das tarefas e papéis maternos. A aquisição do papel materno das mães hansenianas foi interrompido, uma vez que seus filhos foram retirados de seu convívio após o nascimento.

Rubin (1984) ressalta que a identidade materna é construída na gravidez através da imagem de si como mãe e do bebê como filho. No entanto, a realização desse papel de mãe é concretizado através da responsabilidade pelo filho e pelos cuidados voltados para este. As mães hansenianas, apesar de terem construído essa identidade materna, não puderam concretizá-la uma vez que tiveram seus filhos separados no momento do nascimento:

\footnotetext{
A gente só tinha aquele prazer de tá junto com o filho enquanto ele tava no ventre, durante os nove meses. A gente tinha a criança e ela era separada da gente (...) a gente não punha nem as mãos nele. (Esmeralda)
}

Aos 18 anos eu fui mãe, só que levaram meu filho. É uma das coisas tristes da gente daquele tempo. Os pais eram separados dos filhos. Aí me levaram meu filho, eu vi na hora que nasceu, 
não vi mais. (Ametista)

A gravidez, período de espera pelo filho e de preparação para a maternidade no contexto psicossocial, foi vivenciada por uma das entrevistadas como um período de incertezas, principalmente no que diz respeito à saúde do bebê. Esmeralda teve cinco filhos que foram levados para a creche. Tais gestações, bem como a retirada forçada dos filhos, gerou tanto sofrimento que em suas orações ela chegava a pedir a Deus que não lhe desse mais condições de ter filhos, pois todos lhe eram tirados do convívio. A maternidade passa então, a não ser mais desejada:

Eu falava assim com Deus: "Senhor, eu acredito desde menina que o Senhor é o meu pai, o Senhor é o meu criador. Mas eu não acredito que um pai pode criar uma filha leprosa, vivendo dentro de uma colônia, vivendo do jeito que a gente vive, eu e meu marido, isolado de tudo e ter filho. Com tanta pessoa lá fora que tem saúde, que tem condições de tá criando o filho e às vezes não tem condições de ter filho e a gente nessa situação o Senhor dá um filho. O filho vai embora pra creche, separa da gente. É tirado assim ó". (Esmeralda)

Após o nascimento, as crianças eram levadas para a creche, localizada no município vizinho à Colônia. As mães relatam que podiam visitar seus filhos, porém, pobres e sem emprego, essas mães ficavam até meses sem visitar os filhos, pois tinham que fazê-lo com recursos próprios. As visitas eram restritas ao olhar. As mães relatam que ficavam em uma sala e os filhos em outra, separados por uma vidraça: "Os pais só podiam olhar, ver essas crianças, não podia pegar, nem chegar perto, sabe? Ficava a três, quatro metros de distância, só podia ver: Oi meu filho, como que vai e tal." (Rubi); "A gente não podia encostar neles, nem pra dar a benção, tinha que dar a benção de longe. Nem pra pegar na mão deles a gente podia. Quer dizer, se na criança faltasse o pé a gente nem sabia" (Esmeralda).

O modelo de maternidade como papel social da mulher, que lhe atribui todos os deveres e obrigações na criação dos filhos não foi realizado nas colônias que abrigavam os hansenianos. A criação dos filhos ficou a cargo das freiras e às mães coube acompanhar o desenvolvimento de seus filhos através da vidraça.

Borges (2007), em estudo realizado com mulheres hansenianas em que buscou compreender suas experiências de casamento, maternidade e viuvez, relata os sentimentos de indignação tanto das mulheres que eram mães e tiveram seus filhos arrancados como das que não o foram. Este sentimento foi observado na fala das mães, principalmente quando não há a volta desses filhos para casa, como fica ressaltado na fala de Esmeralda: "Eu vim pra colônia, separaram da minha mãe, da minha família, mas eu não era revoltada não, mas quando eu tive o meu primeiro filho eu revoltei, sabe?".

A impossibilidade de realizar o papel de mãe gerou em algumas mulheres o sentimento de revolta até então não experimentado, apesar da separação da família de origem e da rigidez da vida na colônia. Pode-se pensar que tal revolta surge da incerteza sobre o destino da criança. Muitos foram os casos de mães que recebiam a notícia de falecimento de seus filhos e não puderam fazer-lhes uma última visita, nem mesmo visitar seu túmulo. Para essas mães e os demais moradores da colônia, tais crianças não faleceram, mas foram doadas ou vendidas:

E hoje já tem prova que essas crianças foram doadas sem o consentimento dos pais e a gente acredita, pelo horror disso que foram até vendidos, viu? (...) já apareceram pelo menos uma meia dúzia aqui na colônia Santa Izabel, já com seus quarenta, quarenta e poucos anos, procurar seus pais verdadeiros (...) E o pior disso tudo é que eles doavam essas crianças e falavam com os pais que a criança tinha morrido. (Rubi)

Lá na creche eles davam, a maior parte dos filhos da gente foi tudo dado pros outros. Esse meu menino foi dado pros outros, eu tenho certeza, sabe? (...) Eu tenho certeza, porque o meu só coração conta que ele é vivo, não conta que ele morreu. (Esmeralda)

A maternidade é construída na relação, na troca de olhar, no ser-com-o-outro. A não construção dessa relação impediu que essas mães significassem seu papel, após o retorno dos filhos para casa.

A perspectiva futura é uma das características da existência humana (Frankl, 1984). Ao se projetar no futuro o ser humano consegue atribuir sentido ao presente que lhe traz o sofrimento:

Meus meninos já estavam na creche, aí eu peguei e falei pro meu marido assim: "Bem, os nossos meninos tão lá na creche, mas já pensou se algum dia..." isso era Deus falando comigo, né? Já pensou se algum dia eles falarem assim, vocês vão ter que tomar conta dos seus filhos (...). (Esmeralda)

Ao manter a esperança de um dia realizar o papel de mãe, Esmeralda projetava no futuro a esperança de cumprir esta missão. Dessa forma, sua atitude em relação ao sofrimento de não ter os filhos por perto foi o que trouxe um sentido para este momento de sua vida. Frankl (1984) ressalta que as exigências que a vida faz são sempre concretas e variam de um momento para outro.

Mães com filhos: o reencontro com o sentido de ser-mãe. A volta dos filhos para casa exigiu dessas mães uma nova postura diante da vida, agora marcada pelo desafio de conhecer os filhos e de construir uma relação mãe-filho:

Aí tirou as correntes, eles entregaram os filhos pra gente. Só que os filhos não estavam acostumados com a gente, foi um sofrimento. Eu não estava acostumada com eles e eles não estavam acostumados comigo e com o meu marido. Eles estavam acostumados com o ritmo lá deles, das irmãs. (Esmeralda)

Muitos pais tiveram problema com a aceitação dos filhos, que os filhos já vinham criados, cabeça feita. E eles também (os pais) não estavam preparados. O que teve foi os pais pegar cinco, seis filhos, já de cabeça feita e querer que eles tivessem um regime a partir dali do jeito que eles queriam. (Rubi)

A vida questionava novamente essas mulheres. Como ser mãe dessas crianças que elas mal conheciam? Que, apesar de terem sido geradas por elas não se sentem seus filhos e elas não se sentiam suas mães? O distanciamento das crianças de suas famílias impossibilitou o processo de construção dos laços 
familiares o que gerou dificuldades tanto para os pais como para os filhos quando, após a abertura da colônia, estes filhos voltaram para casa.

O fato de as crianças serem criadas longe dos pais e retornarem a casa deles após anos sem sua convivência, além do estranhamento gerava um sentimento de não pertencimento dessas famílias, o que hoje se expressa por distanciamento físico e emocional. As mães relatam que têm filhos que não as procuram e sequer ligam para ter notícias:

Essa minha menina revoltou, foi embora, ela não vem aqui nem pra saber se eu tô viva ou se eu tô morta. Um outro, dos meninos, mais velho que esse que tá aqui, também foi embora, não sei se é vivo ou se é morto, eles não vêm nem pra... nem pra saber se eu ainda existo. (Esmeralda)

As vivências de separação, reencontro e tentativa de construção dos laços familiares constituem marcos nas vidas dos moradores da Colônia que formam as memórias traumáticas do tempo da internação compulsória. As entrevistadas, apesar de dispensarem agora os cuidados para os filhos ainda sentiam uma frustração existencial, o ideal de ser-mãe ainda não fora alcançado.

Frankl (1984) atribui também ao sofrimento inevitável um sentido existencial, uma vez que ele faz parte da vida. Assim, a maneira como a pessoa assume seu destino, assumindo também todo o sofrimento que este lhe propõe, possibilita o encontro com o sentido que ocorre através da descoberta de uma possibilidade de transformar a realidade (Pereira, 2008). A transformação da realidade realizada pelas mães hansenianas foi através da adoção ou de uma gestação que possibilitou o encontro com o sentido de ser mãe.

Silveira e Mahfoud (2008) destacam que apesar dos condicionamentos, a pessoa sempre mantém a liberdade de escolher o que quer dentro das fronteiras que a vida impõe. Reclusas em um hospital colônia, condicionadas pela doença e pelo estigma social que a mesma acarreta pode-se perceber nos discursos a liberdade para realizar escolhas em suas vidas, respondendo a esta através da reconstrução de suas famílias.

Esta capacidade de passar por situações adversas e conseguir superá-las, saindo delas fortalecido, caracteriza o conceito de resiliência (Angst, 2009; Yunes, 2003). Zimmerman \& Arunkumar, (1994), ressaltam que superar as adversidades não significa que o indivíduo saia da crise ileso. As entrevistadas relataram que ainda sentem a falta desses filhos que, segundo elas, foram doados; ao falar neles ainda se emocionam. Ao se considerar que construir resiliência é algo que se faz a cada momento, a cada escolha (Silveira \& Mahfoud, 2008), pode-se perceber que a criação dos demais filhos, netos e filhos de amigos possibilitou a essas mulheres encontrar o sentido de ser mãe.

Os pesquisadores em resiliência identificam fatores de risco e de proteção para o desenvolvimento de comportamento resiliente (Angst, 2009; Silveira \& Mahfoud, 2008; Yunes, 2003). Os fatores de risco podem ser relacionados aos eventos negativos da vida, os quais aumentam a probabilidade do sujeito apresentar problemas físicos, sociais ou emocionais (Yunes \& Szymanski, 2001). As condições do próprio sujeito como tolerância ao sofrimento, habilidade de resolver problemas, entre outros, as condições familiares como qualidade das interações e as redes de apoio em que estão presentes, o reconhecimento do sujeito e sua aceitação são consideradas por Pinheiro (2004) como os fatores protetores, os quais promovem resiliência.

Ser hanseniano, morar em um hospital-colônia, ter convívio social restrito, ser estigmatizado pela sociedade constituíam os fatores de risco para que as famílias entrevistadas cuidassem de seus filhos. Os fatores de proteção encontrados foram o desejo de ser mãe, de cuidar de um bebê e uma forte rede de relações sociais construída por pessoas que passavam pela mesma situação de reclusão.

Silveira e Mahfoud (2008) apontam que o fator protetor mais importante está no relacionamento de apego seguro entre o sujeito resiliente e uma pessoa significativa. Pensando nesta questão encontramos o conceito de "encontro transformador" de Alvarez, Alvarenga e Della Rina (2009). Segundo as autoras, o encontro transformador é a interação entre os seres humanos que possibilita a transformação dos envolvidos visando despertar a retomada do sentido para a vida. Encontramos nos discursos dos entrevistados como esse encontro transformador ocorreu:

Eu tenho uma menina comigo ela não é minha filha, mas é como se fosse. Ela chegou aqui na colônia muito doente mesmo, ela veio na década de 90 e assim a assistente social ficou com dó de colocar ela no pavilhão e procurou alguém que quisesse ficar com ela pra tomar conta e eu fiquei com ela e 'tô' com ela até hoje. Filho legítimo eu só tive um, mas agora tem essa que é praticamente filha. (Ametista)

Uma situação exterior extremamente difícil possibilita ao sujeito a oportunidade de crescer interiormente para além de si mesmo. O conceito de auto-transcendência caracteriza esse viver para além de si que se dirige para algo ou alguém. Dessa forma, ao voltar-se para o outro, o ser humano pode responder às perguntas que a vida lhe faz (Coelho Júnior \& Mahfoud, 2001). No caso das mães hansenianas, a transcendência foi uma resposta à maternidade não vivenciada, apresentada por elas e que as auxiliou no processo de resiliência.

$\mathrm{O}$ encontro com esses filhos adotivos possibilitou o encontro de um sentido para essas vidas que sofreram com as condições biológicas de doença e com o preconceito. A possibilidade de viver aquilo que lhes foi retirado no passado, de buscar um sentido para a existência fez com que as entrevistadas encontrassem na auto-transcendência a realização de suas vidas. Ao voltar-se para o outro que precisa, como no caso de Ametista, viúva e sem filhos, que encontrou uma jovem hanseniana rejeitada pela família de origem devido ao adoecimento, encontra a transformação de sua vida através de um novo sentido, através do amor ao próximo.

Compreendendo que estudar a resiliência significa conhecer as experiências individuais e familiares que foram efetivas e fortalecedoras para o sujeito, frente às adversidades por um período de tempo (Bastos, Alcântara, \& Ferreira-Santos, 2002), podemos pensar que as estratégias de enfrentamento utilizadas pelos entrevistados se apresentam de maneira coletiva mantendo, no entanto, suas particularidades.

Considerado como uma interação entre o indivíduo e o ambiente visando administrar a situação estressora através 
da mobilização de esforços cognitivos e comportamentais, o enfrentamento constitui as estratégias utilizadas pelos sujeitos para lidar com o estressor, manifestando dessa forma, sua capacidade de resiliência (Antoniazzi, Dell'Aglio, \& Bandeira, 1998).

Lazarus \& Folkman (1984) descrevem as estratégias de enfrentamento em dois grandes blocos: um centrado no problema e o outro centrado na emoção. $\mathrm{O}$ enfrentamento centrado no problema está relacionado com os esforços para administrar ou alterar o problema, constituindo estratégias voltadas para a realidade. Uma análise dos discursos das entrevistadas nos possibilita pensar que ao criar os filhos dos amigos ou parentes os sujeitos administram a falta dos filhos biológicos podendo, através destes, encontrar o sentido de família, que não pôde ser realizado:

Eu falava assim: "Meu Deus, eu nunca cuidei de uma criança quer dizer eu tive um tanto de filho, mas eu não sei o que é cuidar de um filho. Eles é que cuidam"... Aí pela misericórdia de Deus eu tive essa menina que é a caçula. Cuidei dela, aí eu tive o prazer de cuidar dela e tudo. (Esmeralda)

O enfrentamento centrado na emoção caracteriza a tentativa de substituir ou regular o impacto emocional gerado pelo fator estressor (Chaves, Cade, Montovani, O’Leite, \& Spire, 2000). Através da adoção ou dos cuidados a bebês, essas mães puderam regular o sofrimento causado pela separação ou perda dos filhos biológicos, além de suprir a vontade de cuidar de crianças pequenas: "Eu tenho uma amiga que pediu pra tomar conta da menina dela. A menina dela tava recém-nascida, aí eu tomei conta da menina e a menina me chama de mãe" (Esmeralda).

Para Silveira e Mahfoud (2008), o vínculo e o sentido são os dois fundamentos básicos da resiliência. Ao estabelecer o vínculo com esses filhos adotivos, as mães hansenianas conseguiram encontrar o sentido de ser mãe e assim resignificaram a falta dos filhos que não voltaram para casa, ou mesmo significaram o sentido do cuidado ao outro. A adoção traz um novo sentido para a vida das mulheres, que acarreta uma mudança significativa em sua forma de se perceber no mundo, trazendo sentido para suas vidas (Maux \& Dutra, 2009).

Viver não significa outra coisa que arcar com a responsabilidade de responder as perguntas que a vida faz pelo cumprimento das tarefas colocadas para cada pessoa na exigência do momento (Frankl, 1984). Ao responder as perguntas da vida o sujeito encontra o sentido que, desempenhado no cotidiano, de acordo com suas peculiaridades, permitem a realização do ser humano (Silveira \& Mahfoud, 2008). As entrevistadas, apesar das dificuldades impostas pela vida, relatam que hoje se sentem realizadas com suas famílias:

Não pude cuidar dos outros, mas Deus me deu a graça de tá cuidando desses três. Deus me recompensou. Que eu não esperava de tá pegando numa criança e ele me deu essa grande graça. Então hoje eu falo, eu não tenho nada pra reclamar, eu tenho só que agradecer a Deus. (Esmeralda)

Segundo Pereira (2008) o homem só se torna homem quando se dedica a uma tarefa ou quando esquece de si mesmo por uma causa ou pelo amor a outra pessoa. Nas mulheres entrevistadas encontramos tanto a causa (ser mãe) como o amor (pelos filhos adotivos) fazendo com que essas mulheres se realizassem como seres humanos.

Frankl (1984) ressalta que o sentido da vida pode acontecer quando o sujeito se encontra com uma situação que não pode ser mudada. Nessas situações não importa o que o sujeito espera da vida, mas sim o que esta espera dele. Dessa forma, a pessoa é desafiada a mudar a si mesma para responder aos questionamentos que a vida lhe faz. Ao serem questionadas sobre o sentido da maternidade, as entrevistadas por muito tempo não tiveram a possibilidade de responder o que era ser mãe, pois só puderam vivenciar a maternidade durante a gravidez. No entanto, uma nova gravidez ou, quando esta não era mais possível, através da adoção, essas mulheres encontraram o sentido de ser-mãe.

\section{Considerações finais}

A busca por uma forma de prevenção da hanseníase e as estratégias adotadas para que a doença não se espalhasse pela população através da internação dos doentes em colônias promoveram a separação das famílias causando impactos emocionais que apesar de serem superados não foram esquecidos.

A forma de lidar com a hanseníase pela saúde pública no século passado pode ser comparada a eventos de violência extrema contra o ser humano, como os campos de concentração da II Guerra Mundial. Esta metáfora é inclusive utilizada pelos pacientes e entidades de defesa como o MORHAN (Savassi, 2010). Mas a própria saúde pública se encarrega de oferecer exemplos similares: a "loucura" foi a herdeira natural da "lepra", tanto na Idade Média quanto no século passado, sendo as pessoas portadoras do sofrimento mental submetidas às mesmas barbáries da hanseníase (Foucault, 1991; Garcia, 2001).

A maternidade, papel tão esperado para as hansenianas da Colônia Santa Izabel, foi uma vivência traumática, que não pôde ser exercida durante os primeiros anos de vida dos filhos, o que dificultou a construção dos laços familiares. Assim, essas mulheres enfrentaram seu destino e o sofrimento com a doença, os tratamentos, a rejeição social e familiar, além do afastamento dos filhos de seu convívio.

Todo esse sofrimento adquiriu um sentido quando essas mulheres foram capazes de ressignificar seu projeto existencial. Essa mudança possibilitou que elas respondessem à vida através do entregar-se ao outro. Na tentativa de exercerem seu papel de mãe, encontraram em uma nova gravidez ou na adoção, a possibilidade de viver aquilo que lhes foi tirado em busca de um ideal higienista.

O encontro transformador vivido por essas mulheres com essas crianças, promoveu o encontro com o sentido da existência que havia sido rompido. Ao adotarem uma criança essas mulheres encontraram a possibilidade de dar sentido ao ser-mãe.

\section{Referências}

Agrícola, E. Situação da lepra no Brasil [Trecho do relatório do Dr. Ernani Agrícola, diretor do Serviço Nacional da Lepra] (1943). Revista do Serviço Nacional da Lepra, 47-85.

Alvarez, A. M. S., Alvarenga, A. T., \& Della Rina, S. C. S. A. (2009). Histórias 
de vida de moradores de rua, situações de exclusão social e encontros transformadores. Saúde e sociedade, 18(2), 259-272.

Angst, R. (2009). Psicologia e resiliência: uma revisão de literatura. Psicologia Argumento, 27(58), 253-260.

Antoniazzi, A. S., Dell'Aglio, D. D., \& Bandeira, D. R. (1998). O conceito de coping: uma revisão teórica. Estudos de Psicologia, 3(2), 273-294.

Bastos, A. C. S., Alcântara, M. A. R., \& Ferreira-Santos, J. E. (2002). Novas famílias urbanas. In E. R. Lordelo, A. M. Carvalho \& S. H. Koller (Orgs.), Infância brasileira e contextos de desenvolvimento (pp. 99-135). São Paulo: Casa do Psicólogo.

Benjamin, A. (2004). A entrevista de ajuda. São Paulo: Martins Fontes.

Borges, V. T. (2007). Casamento, maternidade e viuvez: histórias de mulheres hansenianas. Revista brasileira de história, 27(54), 109-125.

Castro, S. M. S., \& Watanabe, H. A. W. (2009). Isolamento compulsório de portadores de hanseníase: memória de idosos. História, Ciências e Saúde, 16(2), 449-487.

Chaves, E. C., Cade, N. V., Montovani, M. F., Oleite, R. C. B., \& Spire, W. C. (2000). Coping: significados, interferência no processo saúde-doença e relevância para a enfermagem. Revista da Escola de Enfermagem da USP, 34(4), 370-375.

Coelho Júnior, A. G., \& Mafhoud, M. (2001). As dimensões espiritual e religiosa da experiência humana: distinções e inter-relações na obra de Viktor Frankl. Psicologia USP, 12(2), 95-103. Decreto n 7.558 (1938, 11 de novembro). Regulamenta o tratamento dos doentes dentro dos leprosários. Brasília, DF: Presidência da República.

Ducatti, I. (2009). A hanseníase no Brasil na era Vargas e a profilaxia do isolamento compulsório: estudos sobre o discurso científico legitimador. (Dissertação de Mestrado). Universidade de São Paulo, São Paulo.

Dutra, E. (2002). A narrativa como técnica de pesquisa fenomenológica. Estudos de Psicologia, 7(2), 371-378.

Eidt, L. M. (2004). Breve história da hanseníase: sua expansão do mundo para as Américas, o Brasil e o Rio Grande do Sul e sua trajetória na saúde pública brasileira. Saúde e Sociedade, 13(2), 76-88.

Figueiredo, F. S. (2005). Lepra e loucura. (Monografia). Pontifícia Universidade Católica de Minas Gerais, Betim.

Foucault, M. (1991). História da loucura ( $3^{\underline{a}}$ ed.). São Paulo: Perspectiva.

Frankl, V. E. (1984). Em busca do sentido: um psicólogo no campo de concentração. Petrópolis: Vozes.

Garcia, J. R. L. (2001). Entre a "loucura e a hanseníase: interfaces históricas das práticas e políticas instituídas. Hansenologia Internationalis, 26(1), 14-22.

Guerra, A. M. C., Moreira, J. O., \& Diniz, B. (2002). Clínica e inclusão social: novos arranjos subjetivos e novas formas de intervenção. Belo Horizonte: Edições do Campo Social.

Kimura, A. F. (1997). A construção da personagem mãe: considerações teóricas sobre identidade e papel materno. Revista da Escola de Enfermagem da USP, 31(2), 339-343.

Lazarus, R.S., \& Folkman, S. (1984) Stress, appraisal and coping. Nova Iorque: Springer.

Maux, A. A. B., \& Dutra, E. (2009). Do útero à adoção: a experiência de mulheres férteis que adotaram uma criança. Estudos de Psicologia, 14(2), 113-121

Monteiro, Y. N. (1998). Violência e profilaxia: os preventórios paulistas para filhos de portadores de hanseníase. Saúde e Sociedade, 7(1), 3-26.

MORHAN. Movimento de reintegração de pessoas atingidas pela Hanseníase (2006). Colônia Santa Isabel: do estigma à socialização. Betim (MG): MORHAN.

Opromolla, P. A., \& Laurenti, R. (2011). Controle da hanseníase no Estado de São Paulo: análise histórica. Revista de Saúde Pública, 45(1): 195-203.

Pereira, I. S. (2008). Mundo e sentido na obra de Viktor Frankl. Psico, 39(2), 159-165.

Pinheiro, D. P. N. (2004) A resiliência em discussão. Psicologia em Estudo, 9(1), 67-75.

Rubin, R. (1984). Maternal identity ande the maternal experience. Nova Iorque: Springer.

Santos, V. S. M. (2006). Entidades filantrópicas \& políticas públicas no combate à lepra: Ministério Gustavo Capanema (1934-1945). (Dissertação de Mestrado). Casa de Oswaldo Cruz/ FIOCRUZ, Rio de Janeiro. (13925)

Santos, L. A. C., Faria, L., \& Menezes, R. F. (2008). Contrapontos da história da hanseníase no Brasil: cenários de estigma e confinamento. Revista Brasileira de Estudos Populacionais, 25(1), 167-190.

Savassi, L. M. C. (2010). Hanseníase: políticas públicas e qualidade de vida de pacientes e seus cuidadores. (Dissertação de Mestrado). Centro de Pesquisas René Rachou - Fiocruz, Belo Horizonte.

Silveira, D. R., \& Mafhoud, M. (2008). Contribuições de Viktor Emil Frankl ao conceito de resiliência. Estudos de Psicologia. 25(4), 567-576.

Yunes, M. A. M. (2003). Psicologia positiva e resiliência: o foco no indivíduo e na família. Psicologia em estudo, 8, 75-84.

Yunes, M. A. M., \& Szymanski, H. (2001). Resiliência: noção, conceitos afins e considerações críticas. In J.Tavares (Org.), Resiliência e educação (pp.1342). São Paulo: Cortez.

Zimmerman, M. A., \& Arukumar, R. (1994). Resiliency research: implications for schools and policy. Social Policy Report: Society for Research in Child Development, 8(4), 1-18.

Suellen Santos Lima de Almeida, mestranda em Ciências da Saúde no Centro de Pesquisas René Rachou Fiocruz Minas, é psicóloga pela Pontifícia Universidade Católica de Minas. Endereço para correspondência: Avenida Augusto de Lima, 1715, Barro Preto, Belo Horizonte - Minas Gerais. Caixa Postal 1743. CEP 30190-002. Telefone: (31) 3349-7741. E-mail: suellen@cpqrr.fiocruz.br

Leonardo Cançado Monteiro Savassi, mestre em Saúde Coletiva no Centro de Pesquisas René Rachou Fiocruz Minas, é doutorando em Saúde Coletiva pela Fiocruz Minas, é docente na Universidade Federal de Ouro Preto. E-mail: savassi@cpqrr.fiocruz.br

Virgínia Torres Schall, doutora em Educação pela Pontifícia Universidade Católica do Rio de Janeiro, é professora da Pós-Graduação em Ciências da Saúde da Fiocruz Minas. E-mail: vtschall@cpqrr.fiocruz.br Celina Maria Modena, pós-doutora em Saúde Coletiva no Centro de Pesquisas René Rachou - Fiocruz Minas, é professora adjunta do Curso de Gestão de Serviços de Saúde na Universidade Federal de Minas Gerais, é orientadora do Programa de Pós Graduação da Fiocruz - Minas. E-mail: celina@cpqrr.fiocruz.br 